\title{
A Pulverized Coal-Fired Boiler Optimized for Oxyfuel Combustion Technology
}

\author{
Tomáš Dlouhý1 ${ }^{1}$, Tomáš Dupal ${ }^{2}$, Jan Dlouhý$^{1}$ \\ ${ }^{1}$ Czech Technical University in Prague, Faculty of Mechanical Engineering, Department of Energy Engineering, \\ Technická 4, 16607 Prague 6, Czech Republic \\ ${ }^{2}$ Nuclear Research Institute Rez plc, Energoprojekt Prague, Vyskočilova 3/741, 140 21, Prague 4, Czech Republic \\ Correspondence to: tomas.dlouhy@fs.cvut.cz
}

\begin{abstract}
This paper presents the results of a study on modifying a pulverized coal-fired steam boiler in a 250 MWe power plant for oxygen combustion conditions. The entry point of the study is a boiler that was designed for standard air combustion. It has been proven that simply substituting air by oxygen as an oxidizer is not sufficient for maintaining a satisfactory operating mode, not even with flue gas recycling. Boiler design optimization aggregating modifications to the boiler's dimensions, heating surfaces and recycled flue gas flow rate, and specification of a flue gas recycling extraction point is therefore necessary in order to achieve suitable conditions for oxygen combustion. Attention is given to reducing boiler leakage, to which external pre-combustion coal drying makes a major contribution. The optimization is carried out with regard to an overall power plant conception for which a decrease in efficiency due to $\mathrm{CO}_{2}$ separation is formulated.
\end{abstract}

Keywords: CCS, oxyfuel, oxyfuel boiler.

\section{Introduction}

Ecological requirements on greenhouse gas emissions have led to the development of $\mathrm{CO}_{2}$ capture and storage techniques for power facilities. One of these methods is OXYFUEL, which is based on fuel combustion with oxygen. Substituting air by oxygen fundamentally changes not only the combustion conditions but also the flue gas convection and heat transfer in the boiler. These changes have a significant impact on boiler design.

\section{Impact of oxygen combustion on boiler design}

The main benefit of hydrocarbon fuel combustion with oxygen is that the flue gas consists mostly of carbon dioxide and water vapor. Dry, $\mathrm{CO}_{2}$-rich flue gas can be obtained by condensing the water vapor, which simplifies and reduces the cost of $\mathrm{CO}_{2}$ separation for subsequent storage. Large-scale production of oxygen is required for the process. For energetic and economic reasons, oxygen with $95 \%$ purity is extracted from the air by cryogenic distillation. Another consequence of combustion with oxygen instead of air is that the combustion takes place at a high temperature with $1 / 3$ of the flue gas flow rate. The flue gas has a different composition, and therefore dif- ferent physical and chemical properties. These modifications impose new requirements on oxyfuel boiler design, which can be summarized as follows:

1. Flue gas recycling needs to be employed in order to lower the combustion temperature and raise the flue gas flow rate. According to generally presented recommendations, backed up by our own calculations, a $70 \%$ flue gas recycling ratio is considered (i.e. approximately twice the amount of flue gas that forms).

2. The boiler will lack an air preheater. The temperature of the exhaust flue gas will be fairly high, in accordance with the feed water temperature. In order to lower the exhaust temperature, we consider the possibility of employing a flue gas feed water preheater in parallel with the regenerative steam feed water heaters.

3. The boiler has to be perfectly leak-proof. False air suction has to be reduced to an absolute minimum. The reason for this is the radical effect of false air suction on increasing the amount of flue gas and on lowering the $\mathrm{CO}_{2}$ concentration. False air suction needs to be eliminated, even in auxiliary equipment operating at sub-atmospheric pressure, e.g. coal mills and electrostatic precipitators. This requirement cannot be met in practical applications for widely-used beater wheel mills, where the coal is simultaneously dried by the hot flue gas. An external coal drying method is recommended in 
order to separate coal drying from the boiler altogether. A WTA (German abbreviation standing for fluidized-bed drying with internal waste heat utilization) method is proposed for coal drying. In this way, the energetic block efficiency could be raised by several percentage points.

1. The size of the heating surface has to be optimized in order to comply with the power output and steam properties requirements, taking into account the modified heat exchange proportions due especially to the lower flue gas flow and the different substance properties.

\section{Task procedure}

The goal of the task was to elaborate a steam boiler study for consideration in a particular oxyfuel technology application in the conditions of the Czech Republic. The Prunéřov II (EPR II) power plant was selected as a suitable candidate for applying the model. A complex reconstruction is under preparation at the moment, and the disposition offers favorable technology layout conditions. The preparation process for the comprehensive reconstruction is in an advanced stage, and the main technological components, including the boiler, have already been designed. Changes to the boiler design, required for oxygen coal combustion, have been proposed and quantified using thermal calculations. The task has been divided into four phases:

1. The EPR II boiler model was created using the project documentation of the new boiler as a reference case of air combustion.

2. A general boiler modeling software was modified for oxygen combustion.

3. Oxygen combustion with no major changes to the boiler design was calculated - current boiler reconstruction.

4. Boiler design optimization for oxygen combustion was carried out - new equipment design.

\section{Reference boiler and model description}

New once-through two-pass Benson boilers with steam reheating will be installed in the boiler room. This layout best complies with the specific boiler room area and the new boiler placement requirements in the existing supporting structure. The boiler parameters are:

$$
\begin{array}{ll}
\text { Superheated steam } & p=18.262 \mathrm{MPa} \\
& t=575{ }^{\circ} \mathrm{C} \\
& m=183.44 \mathrm{~kg} / \mathrm{s}(660.384 \mathrm{t} / \mathrm{hr}) \\
\text { Reheated steam } & t=580{ }^{\circ} \mathrm{C}
\end{array}
$$

$$
\begin{array}{ll}
\text { Cold reheat steam } & p=3.947 \mathrm{MPa} \\
& t=352.0{ }^{\circ} \mathrm{C} \\
& m=164.826 \mathrm{~kg} / \mathrm{s}(593.376 \mathrm{t} / \mathrm{hr}) \\
\text { Feed water } & p=23.362 \mathrm{MPa} \\
& t=250.9^{\circ} \mathrm{C} \\
& m=660.384 \mathrm{t} / \mathrm{hr}
\end{array}
$$

The boilers are designed for combusting coal with the following properties:

$\begin{array}{lll}\text { Lower heating value } & 9.75 & \mathrm{MJ} / \mathrm{kg} \\ \text { Water content (raw) } & 31 & \% \text { (mass) } \\ \text { Ash (dry) } & 41 & \% \text { (mass) } \\ \text { Sulfur (dry) } & 3.0 & \% \text { (mass) }\end{array}$

The new boiler is shown in Figure 1.

A computation model of the reference boiler was created by inserting the design data into the general steam boiler static operation mode simulation application FFB, created at the Faculty of Mechanical Engineering at CTU in Prague. The model setup consists of the following steps:

- Separate the boiler into balance volumes.

- Enter the connection order of

- Water and steam

- Flue gas

- Air

- Define the heat transfer from flue gas to water/steam/air.

- Specify the geometric characteristics of the furnace and the heating surfaces.

The model was initially tuned for air combustion, so that the operation characteristics matched its design calculation in rated operation mode. This comprises the reference case modeling for further modifications and comparison.

\section{Modifying the model for oxygen combustion}

The general model created for air combustion was modified for oxygen combustion conditions. A fundamental change had to be made to the stoichiometric calculation of the oxidizer and the flue gas volume. A different method had to be used to balance the false air suction and flue gas recycling. On the basis of background research and preliminary computations, the following operating conditions were set for oxygen combustion:

1. Oxygen with $95 \%$ purity will be available. The remaining $5 \%$ is assumed to be a nitrogen-argon mixture.

2. The combustion will operate with a $7 \%$ oxidizer excess.

3. $5 \%$ false air suction is assumed in the furnace (qualified as excess air). 


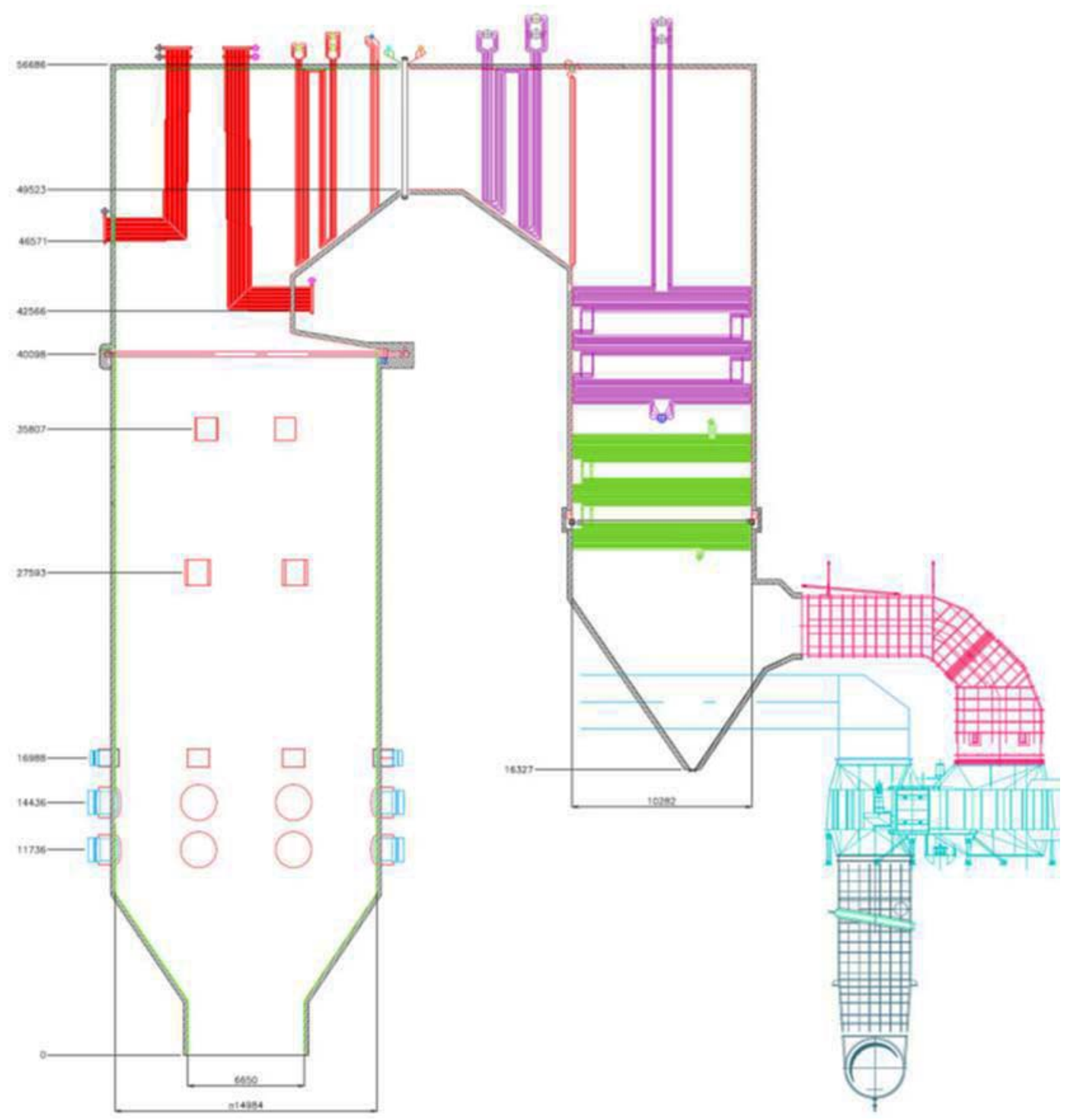

Figure 1: EPR II 250 MWe boiler - Air combustion reference case

4. The recycled flue gas will be extracted downstream from the flue gas filters (upstream from FGD). The recycling rate lies between $66 \%$ and $70 \%$ of the total flue gas flow.

Another significant design change is the addition of external coal drying, utilizing the WTA method. This measure substantially reduces false air suction into the boiler. It is assumed that the coal will be dried to $12 \%$ water content. This will raise its lower heating value and lower the flue gas flow rate, and increase the efficiency of the boiler.

\section{Boiler recalculation for oxygen combustion}

The modified reference boiler model was used for recalculating the oxygen operation mode. In the first stage, the boiler dimensions and the layout and size of the heating surfaces were left unchanged. In this way, the transition from the current boiler operating with air to oxygen combustion was simulated. Only the flue gas recycling was optimized. The calculations showed that it is not possible to match the temperature and flue gas flow rate conditions for both air and oxygen combustion only by regulating the flue gas recycling. The amount of recycled flue gas was set to 2.21 times the amount of the oxidizer flow rate, which represents $67 \%$ of the total flue gas flow rate through the recycling extraction point. In this case, the flue gas temperature downstream from the combustion chamber is the same as in the conventional boiler. However, the flue gas flow rate is $22.6 \%$ lower, which leads to lower flue gas flow velocity through the convective heating surfaces, and therefore their power output is lowered. Superheaters are most affected by this change, since both have a convective characteristic, which leads to reheated steam underheating by 


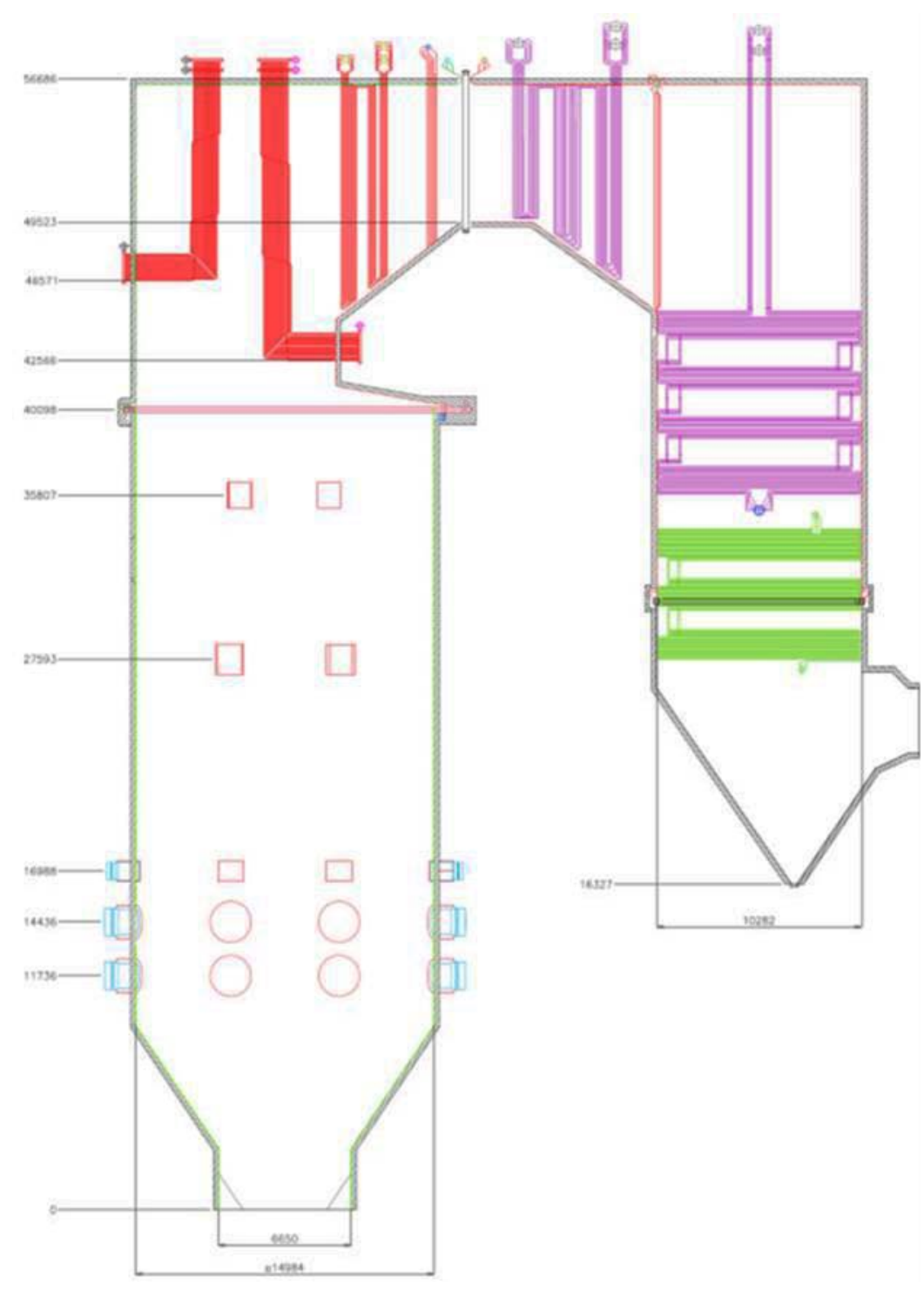

Figure 2: Air boiler modified for oxygen combustion — enlarged reheater

$30{ }^{\circ} \mathrm{C}$ even with full biflux utilization. The absence of an air heater causes the very high flue gas temperature at the outlet of the boiler downstream from the economizer $\left(310^{\circ} \mathrm{C}\right)$. Flue gas recycling may help to some extent to increase the reheated steam temperature at the cost of a further increase in the flue gas outlet temperature, thus downgrading the efficiency of the boiler. On the basis of these results, it can be stated that it is impossible to change the operation mode of the current boiler from air to oxygen simply by employing flue gas recycling while complying with the required steam properties, especially for reheated steam.

The proposed solution to this problem was to enlarge the surface of the steam reheater. A fourth reheater bundle with the same design as the other three was placed in the free space above the first bundle, and one loop of the output reheater was added into the transition pass. The heating surface of the reheater increased by approximately one quar- ter. The boiler with these modifications is shown in Figure 2. The reheater enlargement allowed for a higher reheated steam temperature, though it is still $5{ }^{\circ} \mathrm{C}$ lower than the nominal temperature. Enlarging the reheater has no significant impact on the outlet flue gas temperature.

The calculations indicate it is not a simple matter to reconstruct the current pulverized coal fired boiler from air to oxygen combustion. It would be necessary to utilize flue gas recycling and to modify the heating surface, in particular the reheater and probably also the economizer. The additional necessary modifications to the boiler, e.g. sealing the air leakage, adjusting the airway, and replacing selected surface materials and burners mean that converting the boiler to oxygen combustion might prove to be simply too complicated. It is worth considering replacing the current boiler with a new boiler that has been optimized for oxygen combustion. 


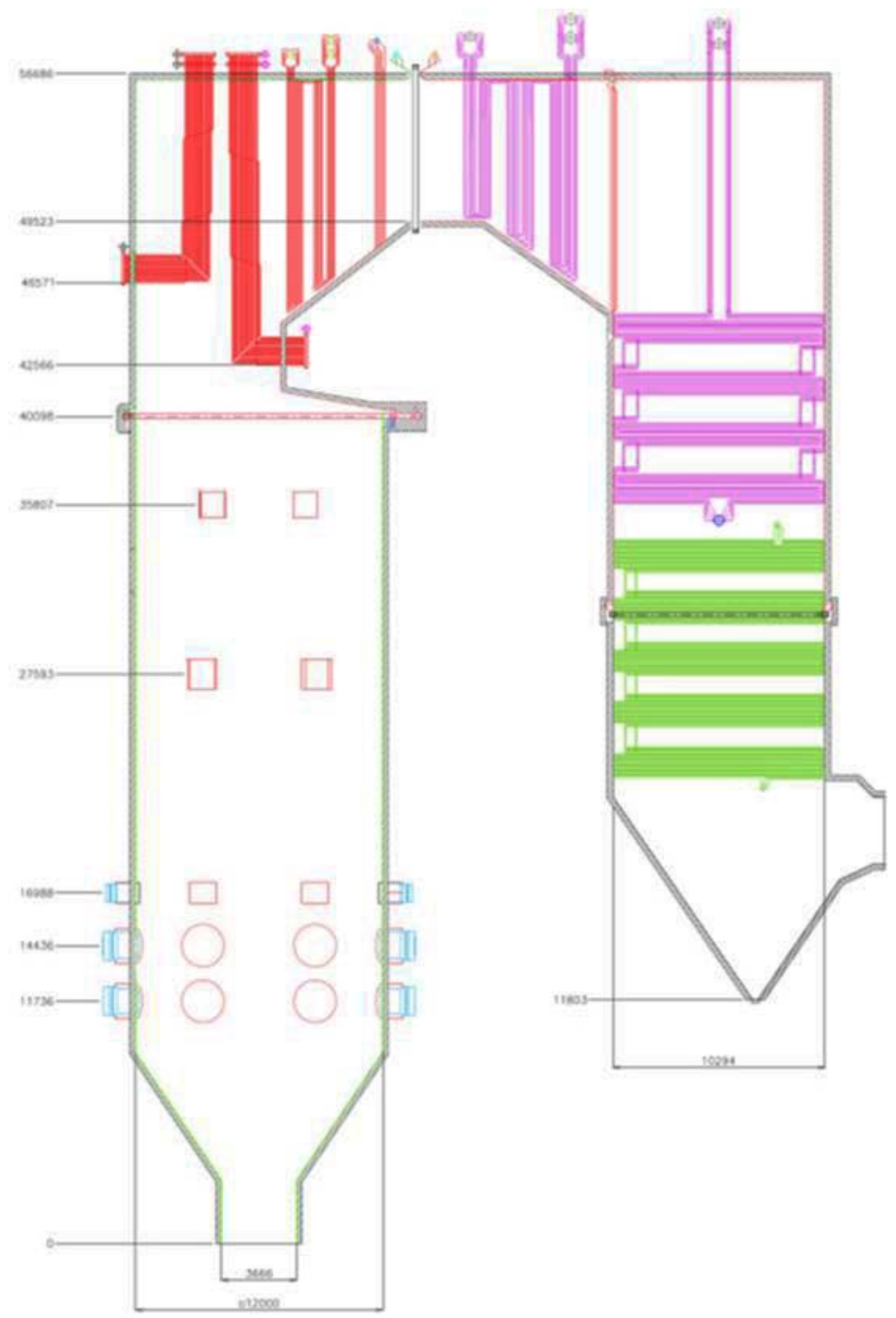

Figure 3: Boiler optimized for combustion with oxygen

\section{Boiler optimization for combustion with oxygen}

The analysis above shows that it is appropriate to modify and optimize the conventional air combustion boiler design for combustion with oxygen. Despite intensive utilization of flue gas recycling, the temperature in the furnace will be higher, and the flue gas flow rate will be lower for oxygen combustion than for air combustion. It is therefore desirable to reduce the size of the radiant heating surfaces, especially the evaporator, and to increase the size of the convective heating surfaces or to thicken the pipe distribution, if this can be done without fouling.

The following design modifications were implemented to optimize the boiler:

1. The size of the evaporator was reduced. The horizontal section of the furnace was scaled down from $14.97 \times 14.97 \mathrm{~m}$ to $12 \times 12 \mathrm{~m}$. The boiler was thus narrowed by approx. 3 meters. The height of the boiler and the side dimension of the second pass remain the same.

2. The number of plates of the superheater in the upper part of the furnace has been preserved, but their span has been reduced to $1.09 \mathrm{~m}$.

3. The pipe span of the output superheater remains unchanged; the size of the output superheater size has been reduced by $19 \%$.

4. A third loop has been added to the output reheater and the traverse span of its pipes has been reduced to $188 \mathrm{~mm}$. The number of parallel pipes has thus been lowered by $10 \%$, and the heating surface has been enlarged by $16 \%$.

5. A fourth bundle has been added to the input reheater, and the pipe span has been reduced to $144 \mathrm{~mm}$, which reduces the diameter of the hanging pipe to $32 \mathrm{~mm}$. The surface is $8 \%$ larger than the surface of the reference boiler.

6. The economizer has been extended by two bundles, and its surface has been increased by $44 \%$. 


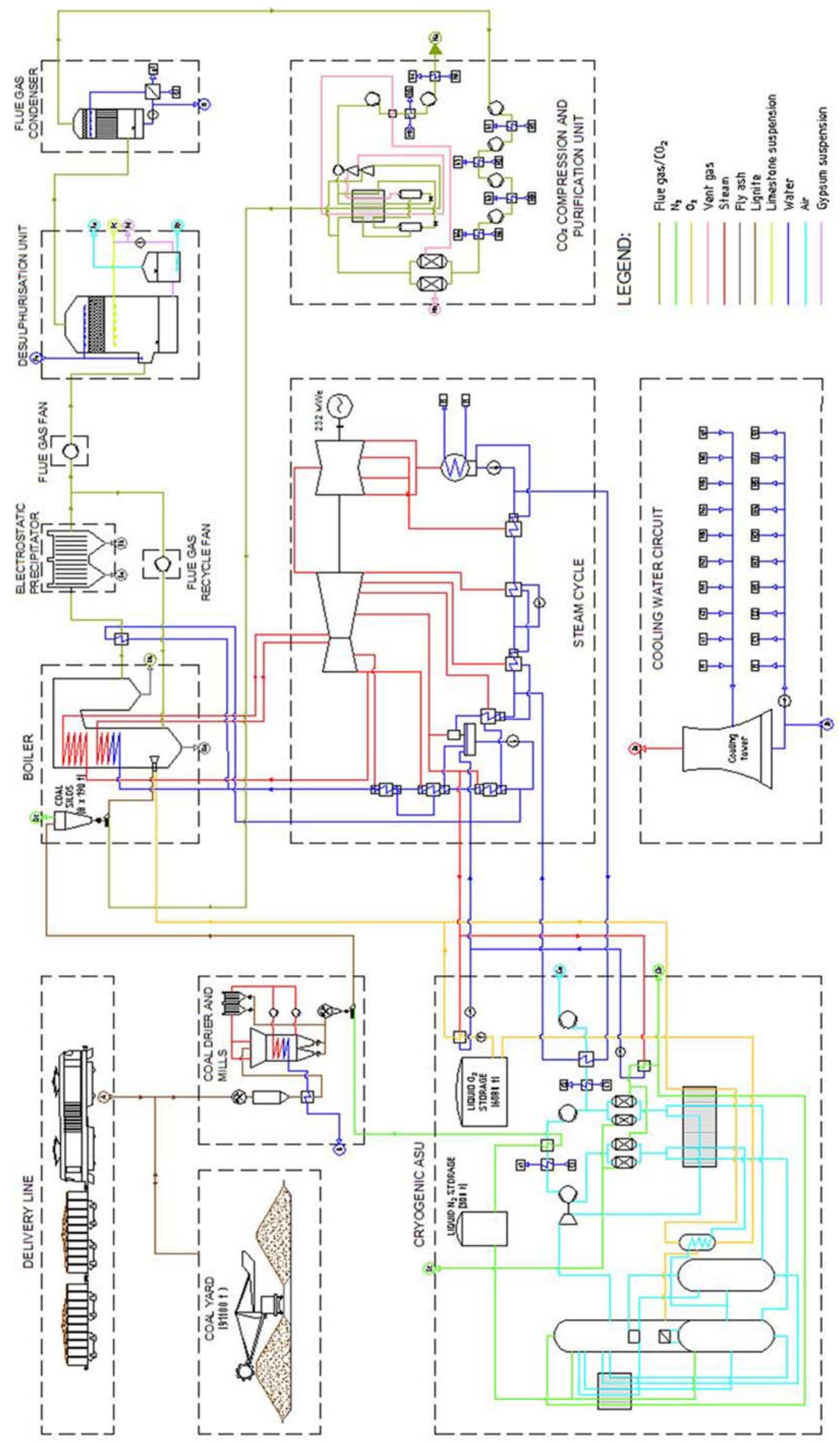

Figure 4: Thermal cycle optimized for oxyfuel technology 
Table 1: Heating surface change

\begin{tabular}{|l|c|c|c|}
\hline & Reference $\left[\mathrm{m}^{2}\right]$ & OXYFUEL $\left[\mathrm{m}^{2}\right]$ & Difference [\%] \\
\hline Economizer & 8823 & 12715 & 144.1 \\
\hline Evaporator & 2149 & 1715 & 79.8 \\
\hline Platen superheater 1 & 357 & 329 & 92.2 \\
\hline Platen superheater 2 & 450 & 422 & 93.8 \\
\hline Output superheater & 1909 & 1552 & 81.3 \\
\hline Input reheater & 7482 & 8077 & 108 \\
\hline Output reheater & 3095 & 3608 & 116.6 \\
\hline
\end{tabular}

The flue gas recycling ratio remains at the previous value.

The furnace was reduced in size so that the flue gas temperature on its outlet remains at approximately the same value as for the reference boiler. This, along with maintaining the same span of the output superheater pipes, should prevent slagging. The heating bundles downstream from the input reheater have a lower pipe span in order to achieve higher flue gas velocity. The possibility of reducing the lateral span of the heating bundles in the second pass is limited by the diameter of the hanging pipes, which has been reduced from $38 \mathrm{~mm}$ to $32 \mathrm{~mm}$. In spite of all efforts, it was not possible to achieve the same flue gas velocity through the heating surfaces as in the reference case; however the difference is quite small. The final sizes of the heating surface are presented in Table 1.

The results of the thermal calculation show that the superheated steam temperature requirement can be met by increasing the size of the superheater, and the flue gas outlet temperature can be lowered to $284^{\circ} \mathrm{C}$ by increasing the size of the economizer. It is difficult to achieve a lower flue gas outlet temperature, due to the low temperature difference equal to $33^{\circ} \mathrm{C}$ in the cold end of the economizer. Further lowering of flue gas temperature would mean a progressive increase in the size of the economizer, for which there is not enough space, and undesirable evaporation could occur with smaller loads. A higher outlet flue gas temperature has no significantly degrading influence on boiler efficiency, since the flue gas flow rate is about a third of the flow rate for the reference case.

\section{Ways of cooling the outlet flue gas}

Some earlier studies assume that the flue gas will be cooled by heating the oxidizer. In our opinion, this is a complicated solution where valuable oxi- dizer can be lost and can leak into the flue gas due to low temperature corrosion, because the acid dew point of the flue gas is around $170{ }^{\circ} \mathrm{C}$. For this reason, an alternative solution featuring flue gas cooling by feed water within the scope of regenerative preheating was taken into consideration for optimizing the thermal cycle. The solution is shown in Figure 4. In this way, it is possible to cool the outlet flue gas down to $200^{\circ} \mathrm{C}$. Although this measure lowers the thermal cycle efficiency, the total contribution to the net unit efficiency is positive by 1.5 percentage points. A further attempt to lower the outlet flue gas temperature by lowering the feed water temperature, achieved by lowering the number of high pressure regenerative heaters, proved to be less effective.

\section{Conclusion}

This paper has presented the latest results of a study on a pulverized coal steam boiler for oxyfuel technology elaborated in scope of research project TIP no. FR-TI1/379, supported by the Czech Ministry of Industry and Trade. The goal is to draw attention to the differences and difficulties in boiler design for combustion with oxygen, and to derive an optimized oxyfuel boiler solution from its air combustion variant. The results indicate that a transition to this technology would require a substantial range of modifications to the existing boilers, which leads us to the recommendation that full-scale replacement of the boiler is a better option. The design of the burner and selection of the materials are challenges that are beyond the scope of this paper.

\section{Acknowledgement}

This paper uses findings resulting from work done on TIP research project no. FR-TI1/379, which was supported by Czech Ministry of Industry and Trade. 


\section{References}

[1] Buhre, B. J. P., Elliott, L. K., Sheng, C. D., Gupta, R. P., Wall, T. F.: Oxy-fuel combustion technology for coal-fired power generation. Progress in Energy and Combustion Science. 31(4), 283-307, 2005.

[2] IEA GHG. Oxy combustion processes for $\mathrm{CO}_{2}$ capture from power plant. Report 2005/9, Cheltenham, UK, IEA Greenhouse Gas R\&D Programme, 212 pp. Jul 2005.

[3] Kakaras, E., Koumanakos, A., Doukelis, A., Giannakopoulos, D., Vorrias, I.: Oxyfuel boiler design in a lignite-fired power plant. Fuel. 86(14), 2 144-2 150, Sep 2007.

[4] Dernjatin, P., Fukuda, Y.: Oxyfuel retrofit to coal power plant (Part 1) - FS of 500 MW class plant.
In $1^{\text {st }}$ oxyfuel combustion conference - book of abstracts, Cottbus, Germany, 8-11 Sep 2009. Cheltenham, UK, IEA Greenhouse Gas R\&D Programme, paper occ1Final00057.pdf, 2 pp, 2009, CD-ROM. Presentation available from: http://www.ieaghg.org/docs/oxyfuel/OCC1/ Session\%206_A/6a_2-BHK_FORTUM.pdf

[5] Dhungel, B., Mönckert, P., Maier, J., Scheffknecht, G.: Oxy-fuel combustion for $\mathrm{CO}_{2}$ abatement during pulverised coal combustion. In International symposium, moving towards zero emission plants, proceedings. Leptokarya, Greece, 20-22 Jun 2005. Ptolemais, Greece, Centre for Research and Technology Hellas, Institute for Solid Fuels Technology and Applications (CERTH/ISFTA), paper 4_01.pdf, 16 pp, 2005, CD-ROM. 